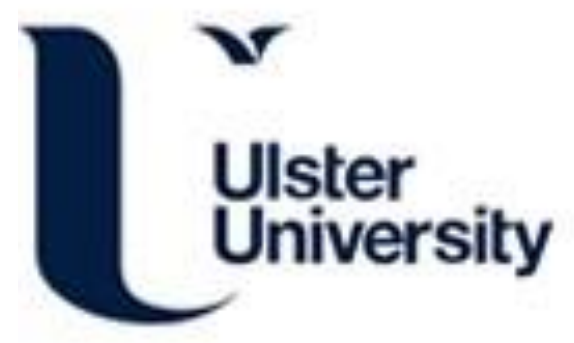

\title{
A study of the effect of thickness on the thermal degradation and flammability characteristics of some composite materials using a cone calorimeter
}

Fateh, T., Kahanji, C., Joseph, P., \& Rogaume, T. (2017). A study of the effect of thickness on the thermal degradation and flammability characteristics of some composite materials using a cone calorimeter. Journal of Fire Sciences, 35, NA-NA. https://doi.org/10.1177/0734904117713690

Link to publication record in Ulster University Research Portal

Published in:

Journal of Fire Sciences

Publication Status:

Published online: 09/06/2017

DOI:

$10.1177 / 0734904117713690$

Document Version

Author Accepted version

\section{General rights}

Copyright for the publications made accessible via Ulster University's Research Portal is retained by the author(s) and / or other copyright owners and it is a condition of accessing these publications that users recognise and abide by the legal requirements associated with these rights.

\section{Take down policy}

The Research Portal is Ulster University's institutional repository that provides access to Ulster's research outputs. Every effort has been made to ensure that content in the Research Portal does not infringe any person's rights, or applicable UK laws. If you discover content in the Research Portal that you believe breaches copyright or violates any law, please contact pure-support@ulster.ac.uk. 
A study of the effect of thickness on the thermal degradation and flammability characteristics of some composite materials using a cone calorimeter

\author{
Talal FATEH ${ }^{a^{*}}$, Charles KAHANJI ${ }^{a}$, Paul JOSEPH ${ }^{b}$ and Thomas ROGAUME ${ }^{\mathrm{c}}$ \\ a) FireSERT, School of the Built Environment and the Built Environment Research Institute, Ulster \\ University, Newtownabbey, BT37 0QB, United Kingdom. \\ b) Centre for Environmental Safety and Risk Engineering, Victoria University, PO Box 14428, \\ Melbourne 8001, Victoria, Australia, \\ c) Institut Pprime, CNRS (UPR-3346), Université de Poitiers, ISAE-ENSMA, F86961 Futuroscope, \\ France. \\ * Corresponding author: Phone: +44 (0) 2890368766 \\ Fax: (+44) (0)28 90368726, Email: t.fateh@ulster.ac.uk
}

\begin{abstract}
In this paper, we report on our investigation regarding the influence of the thickness on the thermal and fire response characteristics of two types of composite materials. For this purpose, carbon fibre-reinforced epoxy and glass fibre-reinforced phenolic resin samples, differing in thicknesses, were chosen. The primary aim was to investigate the effect of using multiple layers on the thermal degradation and fire reaction properties of the composite material using a cone calorimeter. The results showed that the primary fire reaction parameters such as the time-toignition and peak heat release rates PHRR depended on the number of the layers. Furthermore, the amount smoke released during the thermal degradation was found to decrease as the number of layers was increased. In addition, the carbon dioxide emission levels were also observed to be dependent on the number of layers.
\end{abstract}

Keywords: fibre-reinforced composites; epoxy resins; phenolic resins; cone calorimetric tests; fire reaction properties. 


\section{Introduction}

Composite materials are widely used as an alternative to metallic elements in the aerospace industry. Their desirable properties, such as light weight, improved mechanical performance, lower cost and better environmental compatibility are found to be the main advantageous factors for aircraft manufacturers. However, the relatively higher combustibility of these materials is often a limiting factor impeding their wider acceptability in the industry. Furthermore, an enhanced amount of smoke and toxic gases that generally result from the burning of such composites is a real concern as this is likely to impact the evacuation procedure in real fire scenarios.

Therefore, in this context, the real challenge is to formulate composite materials that are mechanically high-performing coupled with a lower overall fire hazard [1-5]

Whilst there are several methods that can be employed to gauge the thermal degradation and fire performance of solids [5], cone calorimetric measurement is the most reliable and frequent used technique [6-7]. Therefore, many investigations describe such a technique to measure the thermal degradation and fire behaviour of several structural composite materials, and a large database is available pertaining to their time-to-ignition, heat release rates, combustion toxicity, etc. $[2,8$ 21]. In many of these studies, the heat release rate is identified as the best indicator of the fire hazard [22], as it can be taken to be directly related to the extent of the fire spread and to other secondary fire hazards. The quantity of heat released from a composite is generally controlled by the combustion of flammable volatiles released from the decomposition of the resin matrix and thus influencing the $\mathrm{CO} / \mathrm{CO}_{2}$ ratio.

There are few reports in the literature that compare the fire resistance properties of the virgin base resinous materials with treated or reinforced counterparts. This also includes some studies on the influence of the number of layers of the constituent material on the thermal degradation and flame retardation [8]. These reports revealed that an increase in the number of layers generally leads to a reduction in the peak value of heat release rate (PHRR) considerably. Furthermore, it was also observed that it resulted in lower time-to-ignition coupled to higher values of the $\mathrm{CO} / \mathrm{CO}_{2}$ ratio. 
Several studies are reported in the literature that deal with downward flame spread rates and extends of thermal transfer for both thin and thick materials [23-29]. Fernandez-Pello et al. [2328] have performed an energy balance, involving gas and solid phases, for the downward flame spread over thick and thin PMMA samples. Generally, the authors have assumed that the heat conduction through the gaseous phase was the dominant mode of heat transfer as the thickness of PMMA test materials was decreased. In another study [24] the researchers extended the applicability of some their previous findings on the downward flame spread over the surface of PMMA sheets of various thicknesses. Furthermore, Hirano et al. [29] calculated the heat of flux at the fuel surface, based on the measured temperature profile for flame spread over sheets of paper. Their main conclusion was also that the heat conduction through the gas phase is the dominant mode of heat transfer through flame spread as gauged through temperature measurements.

In this investigation, two laboratory apparatus have been used. For micro-scale testing, experiments were performed using TGA in nitrogen at 5, 10 and 20C/min in order to explore the thermal stability of carbon fibre-reinforced epoxy resin and glass fibre-reinforced phenolic resin.

For meso-scale, the effect of thickness on the thermal degradation and flammability characteristics of two composite materials (i.e. carbon fibre-reinforced epoxy and glass fibrereinforced phenolic resins) was evaluated through cone calorimetric runs at a pre-set heat flux $50 \mathrm{~kW} \cdot \mathrm{m}^{-2}$.

\section{Experimental}

\subsection{Materials}

The characteristics of the materials tested in the present study are given in Table 1. These materials are expected to be used in the manufacture of the future series of Airbus A350 aircraft.

As can be seen from the table, two kinds of the materials were tested: the carbon epoxy (AcF20 and AcF40) and the glass phenolic composites (AcF 3, AcF 5, AcF7, AcF8 and AcF9). The carbon epoxy had two different thicknesses, i.e. $2.1 \mathrm{~mm}$ and $4.2 \mathrm{~mm}$ as provided by the supplier. The glass phenolic composites on the other hand had five different thicknesses, i.e. 0.8, 1.9, 2.1, 2.2 and $2.3 \mathrm{~mm}$. It can also be noted here that in the case of glass phenolic composites, the 
different thicknesses arose owing to the differences in the number of plies used for manufacturing the materials. In the context of a fire barrier attribute, both carbon epoxy samples were single laminate while all the five glass phenolic specimens were multi laminate. The glass phenolic samples tested had five different plies (3, 5, 7, 8 and 9). According to the manufacturer's data sheet, the supplied carbon epoxy composites contained Bisphenol F Epoxy and Triglycidyl-p-aminophenol as the resin, contributing about $30 \%$ in total composite weight. The phenolic composites, on the other hand, contained glass fibres and were made from Hexply (260) $38 \%$ with a curing temperature of $135^{\circ} \mathrm{C}$.

\subsection{Thermogravimetric analyses}

Thermogravimetric analyses (TGA) were carried out in a Mettler Toledo TGA apparatus, under nitrogen at three heating rates of 5,10 and over $20^{\circ} \mathrm{C} / \mathrm{min}$, and over a temperature range from ambient temperature $\left(30^{\circ} \mathrm{C}\right)$ to $800^{\circ} \mathrm{C}$. The test sample was ground to fine powder using a mechanical grinder before the runs. The TGA furnace and the balance were flushed with nitrogen at a flow rate of $50 \mathrm{ml} / \mathrm{min}$ and $100 \mathrm{ml} / \mathrm{min}$ respectively prior to the tests. The lowest heating rates $\left(<20^{\circ} \mathrm{C} / \mathrm{min}\right)$ are chosen based on a review conducted by Torero [30-31], where it was shown that the output from TGA runs was independent of the heating rates at the lower values.

\subsection{Fire testing}

The fire reaction properties of the specimens were measured using a cone calorimeter according to the standard method prescribed in ISO 5660 [32]. The cone calorimeter is generally considered the most significant bench-scale instrument in fire testing of solid materials. This apparatus is also adopted by the International Organization for Standardization (ISO 5660) for measuring heat release rates (HRR) of test samples. It has been shown that most fuels generate approximately 13.1 MJ of energy per $\mathrm{kg}$ of oxygen consumed [33]. Therefore, the HRR is computed based on the actual amount of oxygen consumed during combustion considering the above principle.

All the samples were tested under a pre-set heat flux of $50 \mathrm{~kW} \cdot \mathrm{m}^{-2}$ (a typical value that is often required for testing aircraft materials). The same value of heat flux was also reported previously 
[8] and is generally higher than that employed in some other studies [34-35]. The operating principles of the oxygen consumption in cone calorimeter method are given in detail elsewhere [6-7]. The size of the sample was $100 \mathrm{~mm} \times 100 \mathrm{~mm}$, with varying thicknesses, and the following parameters were monitored during the tests: time-to-ignition, heat release rates, mass loss, and amounts of carbon monoxide, carbon dioxide and smoke produced.

\subsection{Sample holder}

The sample holder used in the present work is previously described elsewhere [36-37]. In order to minimise the heat loss from the sample, through conduction, a Cotronic paper was used as the insulating material. Furthermore, a layer of aluminium sheet was placed between the sample and the insulating material in order to prevent any melted polymer to permeate into the insulation (this aluminium sheet was very thin, and it is to be assumed here that it only absorbs a very small amount of heat). Figure 1 represents a schematic diagram of the sample holder where the position of the thermocouple (k-type) is also shown.

\section{Results and discussion}

\subsection{TGA results}

Figure 2 shows the thermograms for the composite materials at three different heating rates of 5,10 and $20^{\circ} \mathrm{C} / \mathrm{min}$ - here the results indicated that an increase in the heating rate led to an increase in the induction temperature for the carbon fibre-reinforced epoxy resin. This can be attributed to a slight shift in the degradation pathway(s) with an increase in the heating rate. However, such shifts were not very conspicuous in the thermograms of the glass fibrereinforced phenolic resin.

For the epoxy resin carbon fibre composite, the thermal decomposition mainly occurs between 300 and $500^{\circ} \mathrm{C}$ - at $600^{\circ} \mathrm{C}$, the mass loss is about $25 \%$ of the initial mass. In the case of glass fibre-reinforced phenolic resins, the thermal decomposition mainly occurs between 250 and $600^{\circ} \mathrm{C}$ - here at $600^{\circ} \mathrm{C}$, the mass loss is about $10 \%$ of the initial mass.

\subsection{Cone calorimeter results}

\subsubsection{Time-to-ignition}


Time-to-ignition is an important early indicator of the fire hazard of a material and can be reliably measured in cone calorimetric tests if the specimen undergoes flaming combustion. The time-to-ignition of carbon epoxy and glass phenolic composites are given in Table 2. It can be noticed that for both composites, as expected, the time-to-ignition increased with thickness- this can be primarily attributed to the decrease in the rate of heating with an increase in the thickness of the test specimen.

Figure 3 presents the time-to-ignition as a function of the number of plies (layers) for glassphenolic composite. The relation is found to be quite linear with a correlation coefficient, $\mathrm{R}$, of almost unity. It can be also noted that the epoxy carbon fibre composite, the time-to-ignition for the $(2.1 \mathrm{~mm})$ is higher than of the glass phenolic composite of similar thickness (1.9 and $2.1 \mathrm{~mm})$.

The ignition of solid fuels has been widely investigated, which eventually resulted in the classical theory of ignition, as detailed previously [38]. Here, basically two cases were identified. The first one considered thin objects having no spatial and internal temperature gradients. This case is referred to as 'thermally thin'. The second one, which is called as 'thermally thick', presents a noticeable temperature gradient across the solid fuel. The theory derived from the latter case approximates to the ignition of a solid by considering it as a semi-infinite medium. Here another assumption is made, where the boundary condition of the back surface of the sample has a negligible effect on the final results. From a practical view, the ratio of a material's ability to transfer heat convectively to its ability to transfer heat conductively is defined as the Biot number. This is denoted by $\mathrm{Bi}$, and is shown in the equation 1:

$\mathrm{Bi}=\frac{\mathrm{hL}}{\mathrm{k}}=\frac{\mathrm{R}_{\text {Cond }}}{\mathrm{R}_{\text {Conv }}} \quad$ Equation 1

Where $\mathrm{k}$ is the thermal conductivity, $\mathrm{h}$ the heat transfer coefficient and $\mathrm{L}$ the length.

The Biot number accounts for the convective heat losses in ignitions through a radiant source. However, it the cases of ignitions through convective heat currents, it is assumed to represent the heating phenomena itself. In the present study, the Biot numbers pertaining to the materials are 
presented in table 2 . The corresponding values used for the thermal conductivity were 0.42 and $0.22 \mathrm{~W} / \mathrm{m} . \mathrm{K}$ for epoxy resin carbon and phenolic resin respectively.

Any material with a Biot number that is smaller than 0.1 can be considered as 'thermally thin'. As can be seen, the both samples of the composites varied from 'thermally thin' to 'thermally thick'.

\subsubsection{Heat release rate}

Heat release rates, during the course of a fire, are considered to be the main hazard, especially, in enclosures [39-43]. A higher heat release rate also generally feeds other secondary hazards, such as an enhanced fire spread, secondary ignition, etc. In fact, the peak of the heat release rate is often found to be related to the onset of flashover in the real fire scenarios.

Figure 4 shows the evolution of the heat release rates for the epoxy materials; the presence of two peaks, regardless of the thickness of the material, can be observed here. Furthermore, HRR curve appeared to be moved towards the higher time value as the thickness of the test materials were increased. As can be also seen, the intensity of the first peak decreased as the thickness was increased. This peak can be attributed to the thermal decomposition of the epoxy resin present at the surface of the specimen. The intensity of the second peak, however, was found to be increased as the thickness of the tested material was higher. This peak can be related to the production of flammable gases from the depths of the samples.

The evolution of the heat release rates for the phenolic composite materials as a function of time is plotted in Figure 5. Here again two peaks can be identified for all samples that essentially differed in their thicknesses. The initial peak in HRR can be attributed to surface pyrolysis. The second peak can be thought to arise with an increase in the temperature profile of the material where the unburnt underneath layers were progressively subjected to pyrolysis. Furthermore, the number of plies did not seem to have any significant effect on the peak values of the heat release rate. The char layers thus produced were also observed to have good structural integrity and hence had a better protective action against sustained decomposition of the underlying unburnt matrix. 
Figure 6 presents the evolution of the total heat released as a function of time. It can be noted here that the profiles are somewhat different for samples with varying thicknesses.

The total heat release as a function of the time for the phenolic composites is given in Figure 7here again, the curves are different but have more or less the same profiles, especially at regions below ca. $75 \mathrm{sec}$.

Table 2 presents the peak values of heat release rates and total heat release rate for the different composite materials. For epoxy composites, the PHRR values appeared to be nearly the same regardless of the thickness, while the total heat rate was found have doubled as the thickness was doubled. This can be attributed to the doubling of the epoxy matrix material (i.e. the amount of epoxy resin in the composite with $4.2 \mathrm{~mm}$ thickness is almost twice as the quantity of epoxy resin in the composite having a thickness of $2.1 \mathrm{~mm}$ ).

In the case of the phenolic composites, the PHRR values were found to be only slightly influenced by the number of plies, except for the samples with 3 and 5 plies, where the difference was noticeable. The amount of char formed by the phenolic resins upon thermal degradation can also have an effect on these values. Figure 8 presents the peak heat release rate (PHRR) values as a function of the number of plies for the phenolic composites. As can be seen in Figure 8, some correlation can be observed, between the PHRR and number of plies, expect for the material with 7 plies.

It can also be noted from Figure 8 that the PHRR values ranged between $160 \pm 16 \mathrm{~kW} / \mathrm{m}^{2}$; therefore, the number of layers do not seem to have any significant effect on the values obtained. However, the values of the total heat released was found to depend on the number of plies, with the highest increment as the number of plies is increased from 3 to 5 plies (see Table 3 ). Moreover, the peak heat release rate, as well as the total heat release for epoxy resin (with 2 $\mathrm{mm})$, is higher than those for the corresponding phenolic composite.

\subsubsection{Mass loss}

Table 2 presents the mass loss and the effective heat of combustion at $50 \mathrm{~kW} / \mathrm{m}^{2}$ for the composites. For the carbon fibre-reinforced sample, the mass loss was found to decrease with an 
increase in the thickness - this can be attributed to the differences in the surface temperatures of the two test samples $(2.1 \mathrm{~mm}$ vs $4.2 \mathrm{~mm})$. However, the effective heat of combustion increases slightly with the increase the thickness. It may be due to the high heating rate for the smaller thickness case. For the phenolic composites, the mass loss was observed to increases with a rise in the number plies (from 3 to 7 plies); however, it decreased further on (i.e. from 7 to 9). These changes are plotted in Figure 9. It can be assumed that the composite with 3 or 5 layers (plies) behaved as thermally thin samples - therefore, no temperature gradient existed and all the resins got degraded. However, in the case of specimens with more than 7 plies, a thermally thick behaviour need to be considered where the temperature across the specimens was not uniformthe temperature decreased as the distance from surface increased.

As can be observed from Table 2, the values of the effective heat of combustion for the phenolic composite and carbon fibre epoxy resin were varied according to the thickness. However, the deviation and difference between the behaviours may due to the difference in the behaviour of the char. In the case of carbon fibre-reinforced epoxy resin, the char can be consumed by an oxidative reaction. While for the phenolic composite, a ceramic layer was observed. This layer may need a higher temperature to undergo oxidative reaction(s).

\subsubsection{Carbon monoxide and carbon dioxide production}

The evolutionary profiles of carbon dioxide for the epoxy and the phenolic composites are presented in Figures 10 and 11 respectively. For the epoxy material, the profiles of the $\mathrm{CO}_{2}$ production rate curves were quite different probably owing to the marked difference in the thicknesses.

For phenolic composites, the carbon dioxide production rates did not seem to follow any specific pattern and were found to be influenced by the number of plies.

Table 2 presents the carbon monoxide and carbon dioxide yields for the composites. For the epoxy resin composites, the results showed that the $\mathrm{CO}$ yield increased with an increase in thickness, while the $\mathrm{CO}_{2}$ yield decreased slightly. 
For the phenolic composites, the values for the $\mathrm{CO}$ yields can be observed to be altering with a rise in the number of plies. The $\mathrm{CO}_{2}$ yield was found to increase with an increase in the number of layers from 3 to 5 and from 7 to 9 .

As can be seen, during the thermal degradation of the epoxy resin $(2.1 \mathrm{~mm})$, the amount of CO released was found to be less than those for the corresponding phenolic composite. The same trend wasn't observed in the case of the amount of carbon dioxide released.

\subsubsection{Smoke production}

Figures 12 and 13 present the smoke production rates for the epoxy and phenolic composites respectively. As can be seen, the smoke production rate curves for the epoxy composite consist of two peaks; however, with the two specimens that essentially deferred in thicknesses, the relative intensities of the peaks were also found to be different.

Similarly, the smoke production rate curves for the phenolic composites were presented with two peaks, and the intensity of the first peak was found to decrease with an increase in the number of plies.

Figures 14 and 15 present the total smoke produced as a function of the time for the epoxy and phenolic composites respectively. As can be noticed, the quantity of the smoke released in case of the specimen $4.2 \mathrm{~mm}$ is much higher, especially, after $80 \mathrm{sec}$ that the one which is $2.1 \mathrm{~mm}$ thick- in the latter case the value of the total smoke produced was found to be levelled of past $120 \mathrm{sec}$.

Moreover, as expected, the quantity of smoke for phenolic composite was found to increase with an increase in the number of layers, except for the one with 9 plies. Table 2 presents the smoke yields for the different test samples. As can be seen, an increase in the thickness of the epoxy composites led to an increase in the smoke yield. The value for the epoxy composite having 4.2 $\mathrm{mm}$ thickness is, in fact, twice as compared to the corresponding value for the one which is 2.1 mm thick. Similarly, the smoke yields increased with an increase in the number of plies in the case of the phenolic resins. 
Figure 16 presents the correlation between the smoke yield and the number of layers (i.e. plies) used in glass phenolic composite. Here, it can be observed that the relation presents a linear trend.

\section{Main conclusions}

The present article presents the results pertaining to the variation in thicknesses of two types of fibre-reinforced composite materials, on the fire reaction properties, obtained primarily through cone calorimetric tests under a pre-set heat flux of $50 \mathrm{~kW} \cdot \mathrm{m}^{-2}$.

The following conclusions can be drawn from the present study:

- The time-to-ignition ( $\mathrm{t}_{\mathrm{ig}}$ ) was found to be higher as the thickness increased - this can be attributed to the lower heating rates that eventually led composite materials to their ignition temperature. Here a linear relation was found between the number of layers and the corresponding time-to-ignition in the case of the phenolic resins.

- The total heat released was observed to increase with an increase in the number layers, or thickness - this could be due to the increase in the amount of combustible material as the thickness of the test specimens increased. However, the value for the peak of heat release rate for the epoxy composites was found to be independent of the thickness, while the PHRRs were found to be enhanced as the number of layers of the composites increased. Also, a linear relation between the values of the PHRR and number of layers was observed.

- The $\mathrm{CO}_{2}$ yields decreased as the thickness of epoxy composite increased, while the $\mathrm{CO}$ yields were observed to be higher. However, no such relation was found for the phenolic composites (it is to be noted here that the $\mathrm{CO}_{2}$ yields were found to be higher as the number of layers increased from seven to nine plies.

- Generally, the smoke yields were found to have increased as the number of layers (or thickness) increased.

- It is quite evident that the uncertainties for all the fire parameters measured in this study are higher for the phenolic resin composites than the other composite materials. Some of these uncertainties could stem from the difference in the homogeneity of the test samples 
occurred at their production stage, and also owing to possible drifts in the response signals as measured by the oxygen analyser that went beyond an acceptable level of tolerance.

During the experiments, generally, the thermal degradation of the phenolic composites generated a structurally compact ceramic type protective layer. The stability of these layers was also found to be influenced by the number of layers. The protective layers so formed can be assumed to impede the escape of combustible vapours and other gases and decrease the permeability of the air and the heat in solid depth. The conditions and the actual mode of formation of such layers warrant further investigations.

\section{References}

1. B.K. Kandola, A.R. Horrocks, P. Myler, D. Blair, Mechanical performance of heat/fire damaged novel flame retardant glass-reinforced epoxy composites, Composites Part A: Applied Science and Manufacturing. 34 (2003) 863-873.

2. A.P. Mouritz, S. Feih, E. Kandare, Z. Mathys, A.G. Gibson, P.E. Des Jardin, S.W. Case e, B.Y. Lattimer, Review of fire structural modelling of polymer composites, Composites Part A: Applied Science and Manufacturing. 40 (2009) 1800-1814.

3. B.K. Kandola, A.R. Horrocks, P. Myler, D. Blair, New developments in flame retardancy of glass - reinforced epoxy composite, Journal of Applied Polymer Science. 88 (2003) 2511-2521.

4. B.K. Kandola, A.R. Horrocks, Complex char formation in flame retarded fibreintumescent combinations: II. Thermal analytical studies, Polymer Degradation and Stability. 54 (1996) 298-303.

5. R. Filipczak, S. Crowley, R.E. Lyon, Heat release rate measurements of thin samples in the OSU apparatus and the cone calorimeter, Fire Safety Journal. 40 (2205) 628-645.

6. ASTM E 1354-97, Standard test method for heat and visible smoke release rates for materials and products using an oxygen consumption calorimeter, American Society for Testing of Materials, West Conshohocken, PA (1997).

7. V. Babrauskas, The cone calorimeter, SFPE handbook of fire protection engineering, Section 3 (3rd ed), National Fire Protection Association, Quincy, MA (2002) 63-81. 
8. T.M. Kotresh, R. Indushekar, M.S. Subbulakshmi, S.N. Vijayalakshmi, A.S. Krishna Prasad, K. Gaurav, Evaluation of foam/single and multiple layer Nomex fabric combinations in the cone calorimeter, Polymer Test. 24 (2005) 607-612.

9. A. Tewarson, D.P. Macaione, Polymers and composites - an examination of fire spread and generation of heat and fire products, Journal of Fire Sciences. 11 (1993) 421-41.

10. M.J. Scudamore, Fire performance studies on glass-reinforced plastic laminates, Fire and Materials. 18 (1994) 313-25.

11. J.R. Brown, P.D. Fawell, Z. Mathys, Fire-hazard assessment of extended-chain polyethylene and aramid composites by cone calorimeter, Fire and Materials. 18 (1994) $167-72$.

12. G.T. Egglestone, D.M. Turley, Flammability of GRP for use in ship superstructures, Fire and Materials. 18 (1994) 255-60.

13. F.Y. Hshieh, H.D. Beeson, Flammability testing of flame-retarded epoxy composites and phenolic composites, Fire Mater. 21 (1997) 41-49.

14. A.T. Grenier, N.A. Dembsey, J.B. Barnett, Fire characteristics of cored composite materials for marine use, Fire Safety Journal. 30 (1998) 137-59.

15. A.P. Mouritz, Review of smoke toxicity of fiber-polymer composites used in aircraft, Journal of Aircraft. 46 (2009) 737-45.

16. J.P. Fanucci, Thermal response of radiantly heated kevlar and graphite/epoxy composites, Journal of Composite Materials. 21 (1987) 129-39.

17. H.J. Ott, Thermal conductivity of composite materials, Plastics and Rubber Processing and Applications. 1 (1981) 9-24.

18. P. Gu, R.J. Asaro, Distortion of polymer matrix composite panels under transverse thermal gradients, Composite Structures. 82 (2008) 413-21.

19. P. Gu, R.J. Asaro, Wrinkling of sandwich polymer matrix composite panels under transverse thermal gradients, Fire Safe Journal. 43 (2008) 151-60.

20. C.I. Chang, Thermal effects on polymer composite structures, Theoretical and Applied Fracture Mechanics. 6 (1986) 113-20.

21. G.A. Pering, P.V. Farrell, G.S. Springer, Degradation of tensile and shear properties of composites exposed to fire or high temperature. Journal of Composite Materials. 14 (1989) 54-66. 
22. R.E. Lyon, Advanced fire safe aircraft materials research programme. Technical report DOT/FAA/CT-94/60 (1994).

23. E.A. Abulbaida, Experimental study of downward flame spread rate on PMMA. Ph.D. Thesis. Dalhousie University Halifax, Nova Scotia May 2014. Canada.

24. A.C. Fernandez-Pello, T. Hirano, Controlling mechanisms of flame spread. Fire Science and Technology. 2 (1982) 17-54. doi:10.3210/fst.2.17.

25. A.C. Fernandez-Pello, F.A. Williams, Laminar flame spread over PMMA surfaces, Symposium (International) on Combustion. 15 (1975) 217-231.

26. A.C. Fernandez-Pello, F.A. Williams, A theory of laminar flame spread over flat surfaces of solid combustibles, Combustion and Flame. 28 (1977), 251-277.

27. A.C. Fernandez-Pello, R.J. Santoro, On the dominant mode of heat transfer in downward flame spread, Symposium (International) on Combustion. 17 (1979) 1201-1209.

28. A.C. Fernandez-Pello, S.R. Ray, I. Glassman, Flame spread in an opposed forced flow: The effect of ambient oxygen concentration, Symposium (International) on Combustion. 18 (1981) 579-589.

29. T. Hirano, S.E. Noreikis, T.E. Waterman, Measured velocity and temperature profiles near flames spreading over a thin combustible solid, Combustion and Flame. 23 (1974) 83-96.

30. J.L. Torero, Flaming ignition of solid fuels. The SFPE Handbook of Fire Protection Engineering, 4th Edn, chapter 11. National Fire Protection Association: Quincy, MA, USA, 2008; 2-262.

31. T. Fateh, F. Richard, T. Rogaume, P. Joseph, Experimental and modelling studies on the kinetics and mechanisms of thermal degradation of polymethyl methacrylate in nitrogen and air, Journal of Analytical and Applied Pyrolysis 120 (2016) 423-433.

32. ISO 5660-1. Reaction-to-fire tests - Heat release, smoke production and mass loss rate Part 1: Heat release rate (cone calorimeter method) and smoke production rate (dynamic measurement). International standards Organisation, Geneva, Switzerland, (2015).

33. C. Hugget, Estimation of rate of heat release by means of oxygen consumption measurements, Fire and Materials. 4 (1980) 61-65. 
34. D. Price, Y. Liu, T.R. Hull, G.J. Milnes, B.K. Kandola, A.R. Horrocks, Burning behaviour of foam/cotton fabric combinations in the cone calorimeter, Polymer Degradation and Stability. 77 (2002) 213-220.

35. M. Checchin, C. Cecchini, B. Cellarosi, F.O. Sam, Use of cone calorimeter for evaluating fire performances of polyurethane foams, Polymer Degradation and Stability. 64 (1999) 573-576.

36. J.L. De Ris, M. M. Khan, A sample holder for determining material properties, Fire and Materials. 24 (2000) 219-226.

37. M. Delichatsios, B. Paroz, A. Bhargava, Flammability properties for charring materials, Fire Safety Journal. 38 (2003) 219-228.

38. J. Quintiere, A Semi-quantitative Model for the Burning Rate of Solid Materials, NISTIR 4840 National Institute of Standards and Technology, Gaithersburg, MD (1992).

39. V. Babrauskas, R.D. Peacock, Heat release rate: the single most important variable in fire hazard, Fire Safety Journal. 18 (1992) 255-272.

40. V. Babrauskas, Why was the fire so big? HHR: The role of heat release rate in described fires, Fire and Arson Investigation. 47 (1997) 54-57.

41. V. Babrauskas, The cone calorimeter, SFPE handbook of fire protection engineering, Section 3 (3rd ed), National Fire Protection Association, Quincy, MA (2002) 63-81.

42. R.E. Lyon, Fire safe aircraft cabin materials, G.L. Nelson (Ed.), Fire and polymers. ACS symposium series 599, American Chemical Society, Washington, DC (1995) 618.

43. B. Schartel, U. Braun, U. Schwarz, S. Reinemann, Fire retardancy of polypropylene/flax blends, Polymer. 44 (2003) 6241-6250. 
Table 1: Details of the composites tested.

\begin{tabular}{|l|l|l|l|l|l|l|l|}
\hline $\begin{array}{l}\text { Sample } \\
\text { specification }\end{array}$ & AcF20 & AcF40 & AcF 3 & AcF 5 & AcF7 & AcF8 & AcF9 \\
\hline Fibre & Carbon & Carbon & Glass & Glass & Glass & Glass & Glass \\
\hline Matrix & Epoxy & Epoxy & Phenolic & Phenolic & Phenolic & Phenolic & Phenolic \\
\hline Fire barrier & Single laminate & Single laminate & $\begin{array}{l}\text { Woven } \\
\text { laminate }\end{array}$ & $\begin{array}{l}\text { Woven } \\
\text { laminate }\end{array}$ & $\begin{array}{l}\text { Woven } \\
\text { laminate }\end{array}$ & $\begin{array}{l}\text { Woven } \\
\text { laminate }\end{array}$ & $\begin{array}{l}\text { Woven } \\
\text { laminate }\end{array}$ \\
\hline Layup & {$[-135 / 90 / 45 / 0]$} & {$[-135 / 90 / 45 / 0]$} & 3 plies & 5 plies & 7 plies & 8 plies & 9 plies \\
\hline Thickness & $2.1 \mathrm{~mm}$ & $4.2 \mathrm{~mm}$ & $0.8 \mathrm{~mm}$ & $1.9 \mathrm{~mm}$ & $2.1 \mathrm{~mm}$ & $2.2 \mathrm{~mm}$ & $2.3 \mathrm{~mm}$ \\
\hline
\end{tabular}

Table 2: the main parameters measured for the composite materials at $50 \mathrm{~kW} \cdot \mathrm{m}^{-2}$.

\begin{tabular}{|c|c|c|c|c|c|c|c|}
\hline Sample specification & $\begin{array}{c}\text { AcF20 } \\
2 \mathrm{~mm}\end{array}$ & $\begin{array}{c}\text { AcF40 } \\
4 \mathrm{~mm}\end{array}$ & $\begin{array}{c}\text { AcF 3 } \\
3 \text { plies }\end{array}$ & $\begin{array}{c}\text { AcF 5 } \\
5 \text { plies }\end{array}$ & $\begin{array}{c}\text { AcF7 } \\
7 \text { plies }\end{array}$ & $\begin{array}{c}\text { AcF8 } \\
8 \text { plies }\end{array}$ & $\begin{array}{c}\text { AcF9 } \\
9 \text { plies }\end{array}$ \\
\hline Ignition time, $\mathrm{t}_{\text {ig }}(\mathrm{s})$ & $30 \pm 1$ & $49 \pm 2$ & $9 \pm 1$ & $17 \pm 1$ & $24 \pm 2$ & $27 \pm 3$ & $31 \pm 1$ \\
\hline $\begin{array}{c}\text { Biot Number } \\
\begin{array}{c}\text { Peak heat release rate } \\
\left(\mathrm{kW} / \mathrm{m}^{2}\right)\end{array}\end{array}$ & 0.05 & 0.1 & 0.036 & 0.086 & 0.096 & 0.1 & 0.11 \\
\hline $\begin{array}{c}\text { Total heat release } \\
\left(\mathrm{MJ} / \mathrm{m}^{2}\right)\end{array}$ & $19.6 \pm 1.5$ & $39.9 \pm 3.7$ & $4.5 \pm 1$ & $13.2 \pm 1.5$ & $15.5 \pm 2.1$ & $11.1 \pm 1$ & $15.9 \pm 1.6$ \\
\hline Mass loss \% & $35.5 \pm 2$ & $28.2 \pm 2$ & $26.1 \pm 6$ & $35 \pm 7.6$ & $39 \pm 3.4$ & $28.9 \pm 4$ & $17.2 \pm 2.4$ \\
\hline$\Delta \mathrm{H}_{\mathrm{c}}$ & $16.2 \pm 0.4$ & $19.9 \pm 0.7$ & $17.6 \pm 6$ & $19.1 \pm 5$ & $19.1 \pm 5.5$ & $18.0 \pm 2.7$ & $19.7 \pm 2$ \\
\hline $\mathrm{CO}$ yield & $0.04 \pm 0.01$ & $0.1 \pm 0.01$ & $0.51 \pm 0.2$ & $0.36 \pm 0.13$ & $0.65 \pm 0.05$ & $0.21 \pm 0.07$ & $0.47 \pm 0.1$ \\
\hline $\mathrm{CO}$ yield & $1.68 \pm 0.2$ & $1.5 \pm 0.05$ & $1.29 \pm 0.38$ & $1.49 \pm 0.15$ & $1.16 \pm 0.05$ & $1.19 \pm 0.14$ & $1.63 \pm 0.1$ \\
\hline Smoke yield & $0.05 \pm 0.002$ & $0.1 \pm 0.01$ & $0.08 \pm 0.03$ & $0.08 \pm 0.02$ & $0.15 \pm 0.01$ & $0.22 \pm 0.01$ & $0.22 \pm 0.01$ \\
\hline
\end{tabular}


Figure 1: sample holder.

Figure 2: Thermograms of the composites under nitrogen at three different heating rates 5,10 and $20^{\circ} \mathrm{C} / \mathrm{min}$.

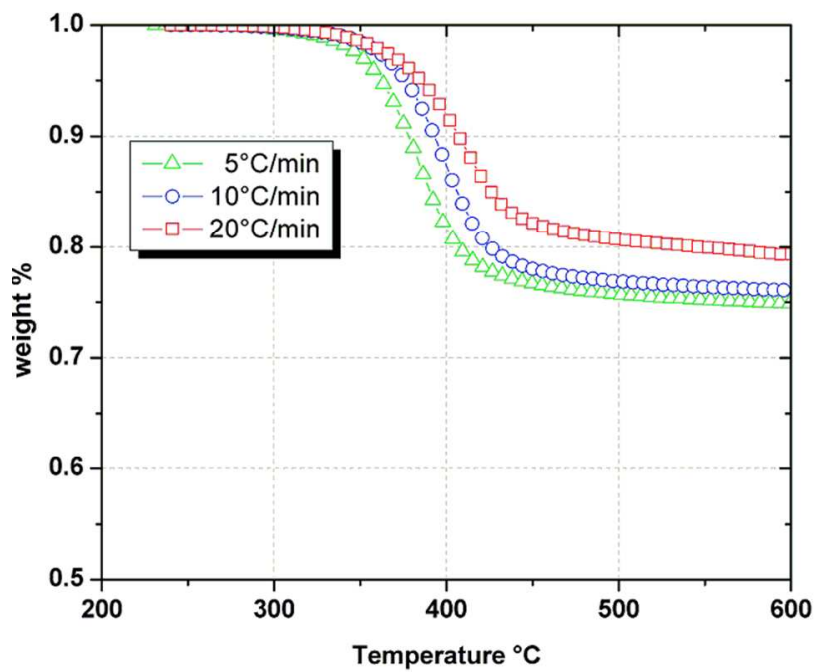

Carbon fibre-reinforced epoxy resin

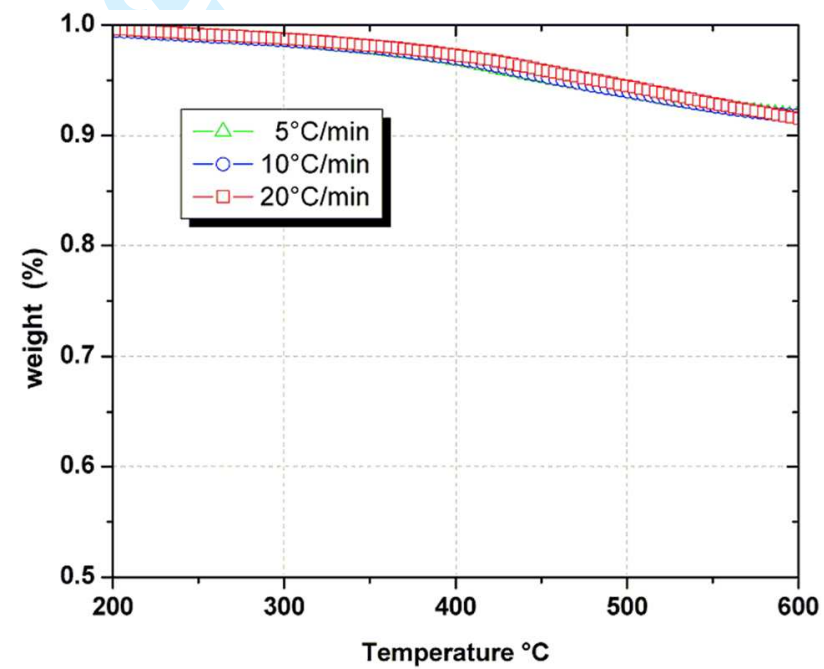

Glass fibre-reinforced phenolic resin 
Figure 3: Plot of the time-to ignition as a function of number of plies for phenolic resins.

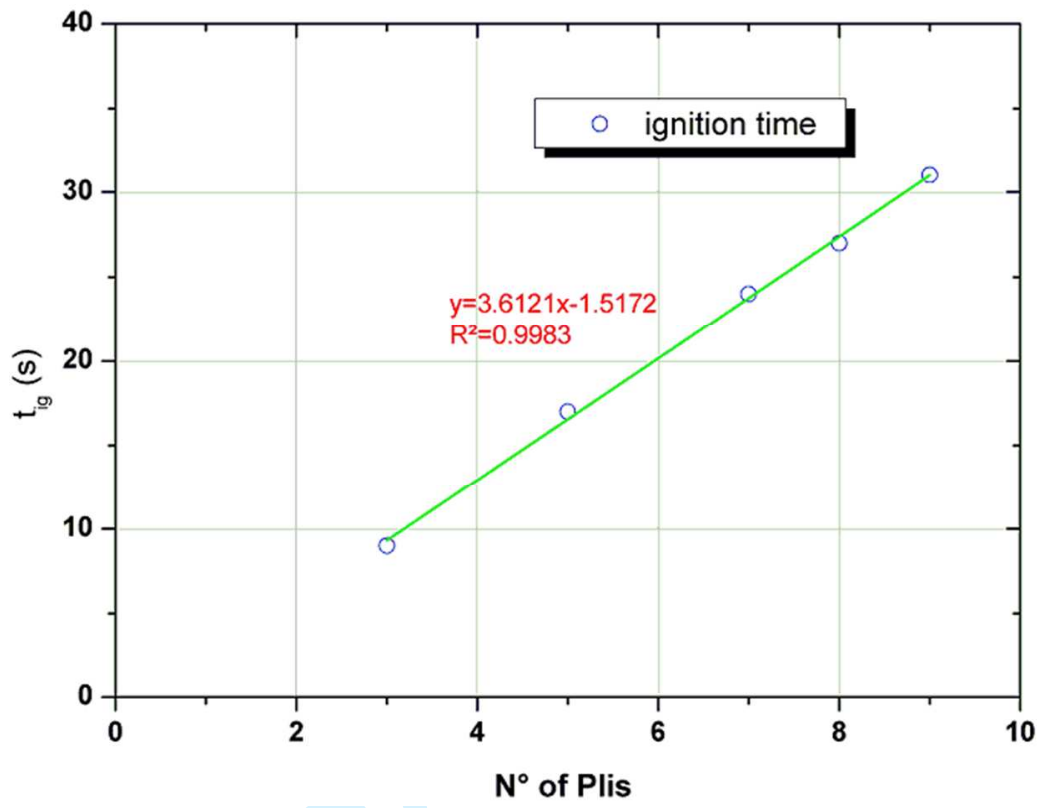

Figure 4: HRRs for the epoxy materials as a function of time at $50 \mathrm{~kW} / \mathrm{m}^{2}$.

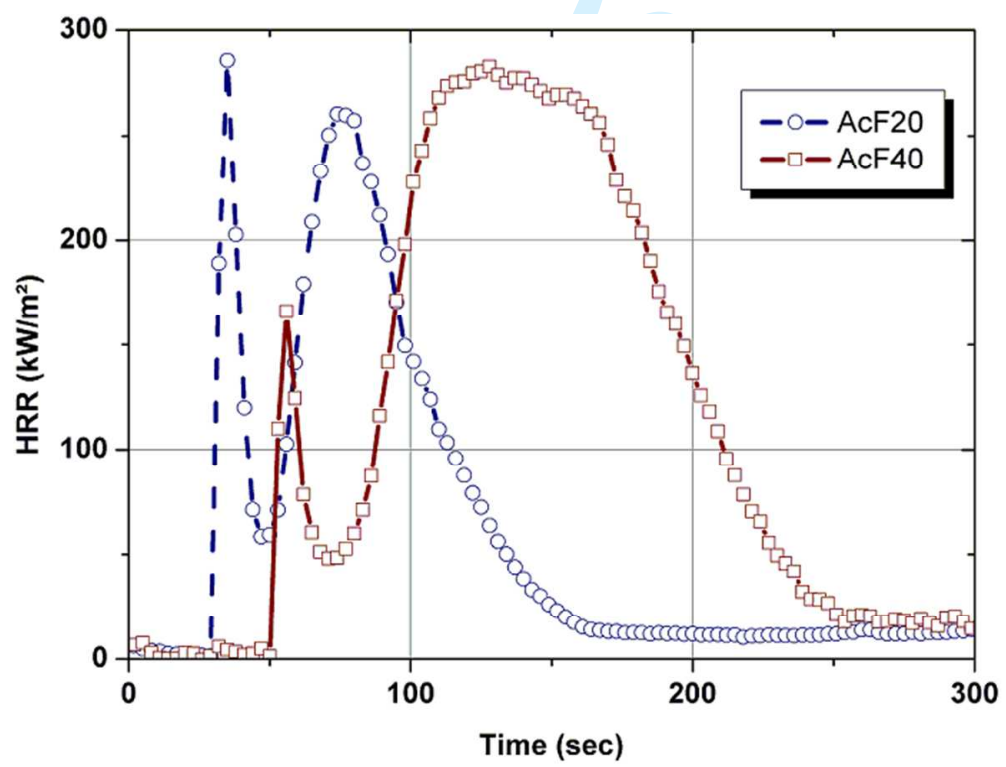

https://mc.manuscriptcentral.com/jfsciences 
Figure 5: HRRs for glass-phenolic composite materials as a function of time at $50 \mathrm{~kW} / \mathrm{m}^{2}$.

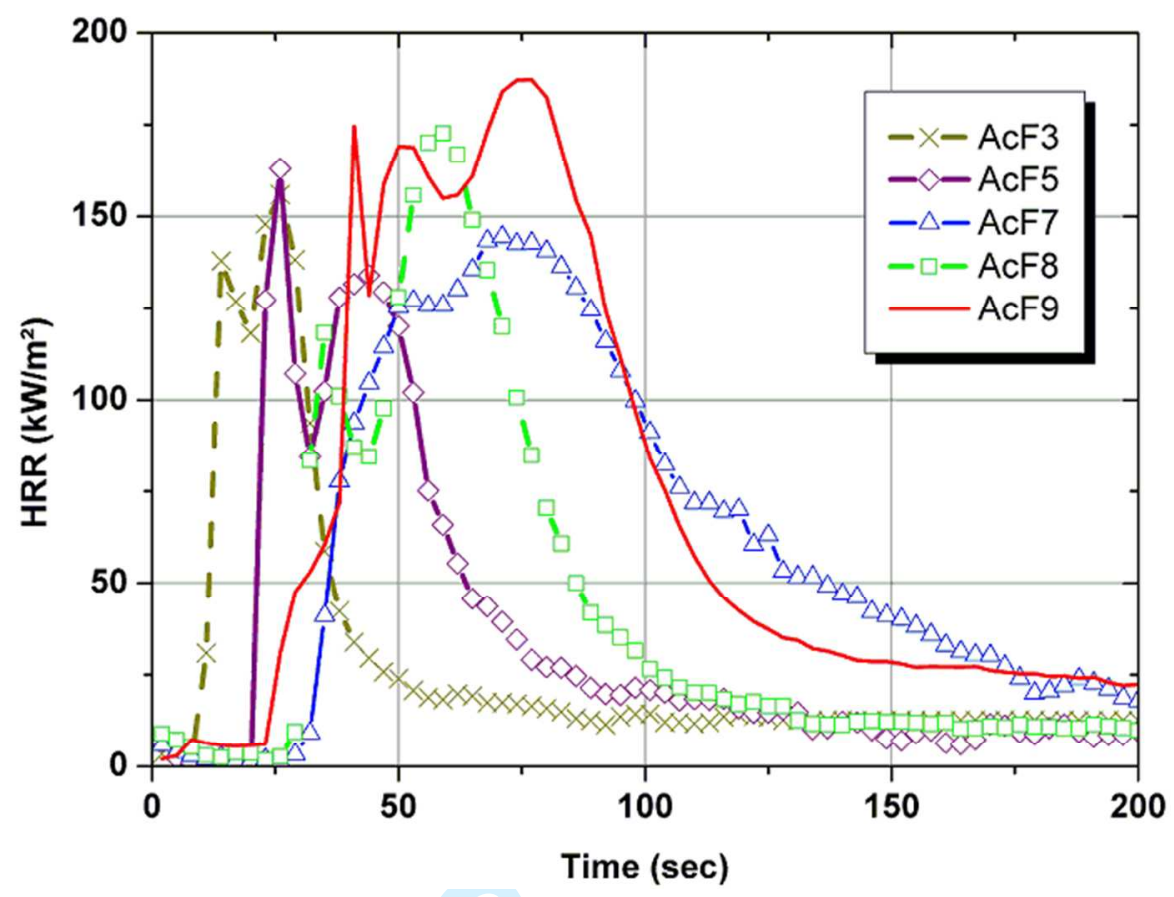

Figure 6: THR profiles for epoxy composite materials as a function of time at $50 \mathrm{~kW} / \mathrm{m}^{2}$.

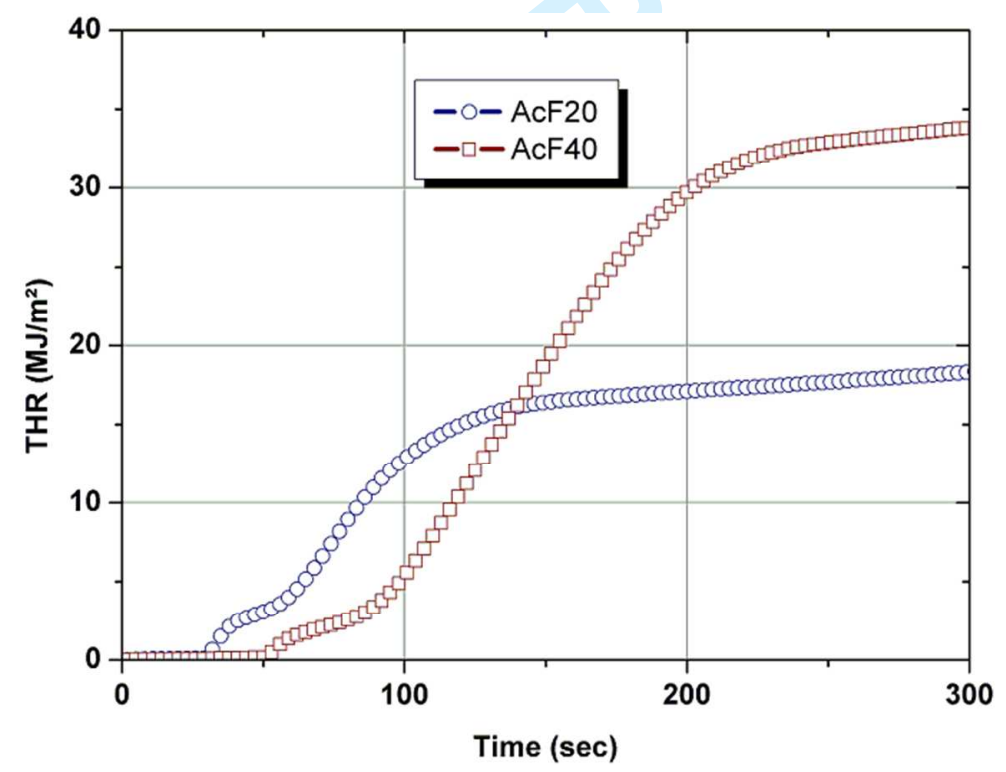

https://mc.manuscriptcentral.com/jfsciences 
Figure 7: THR for phenolic composite materials as a function of time at $50 \mathrm{~kW} / \mathrm{m}^{2}$.

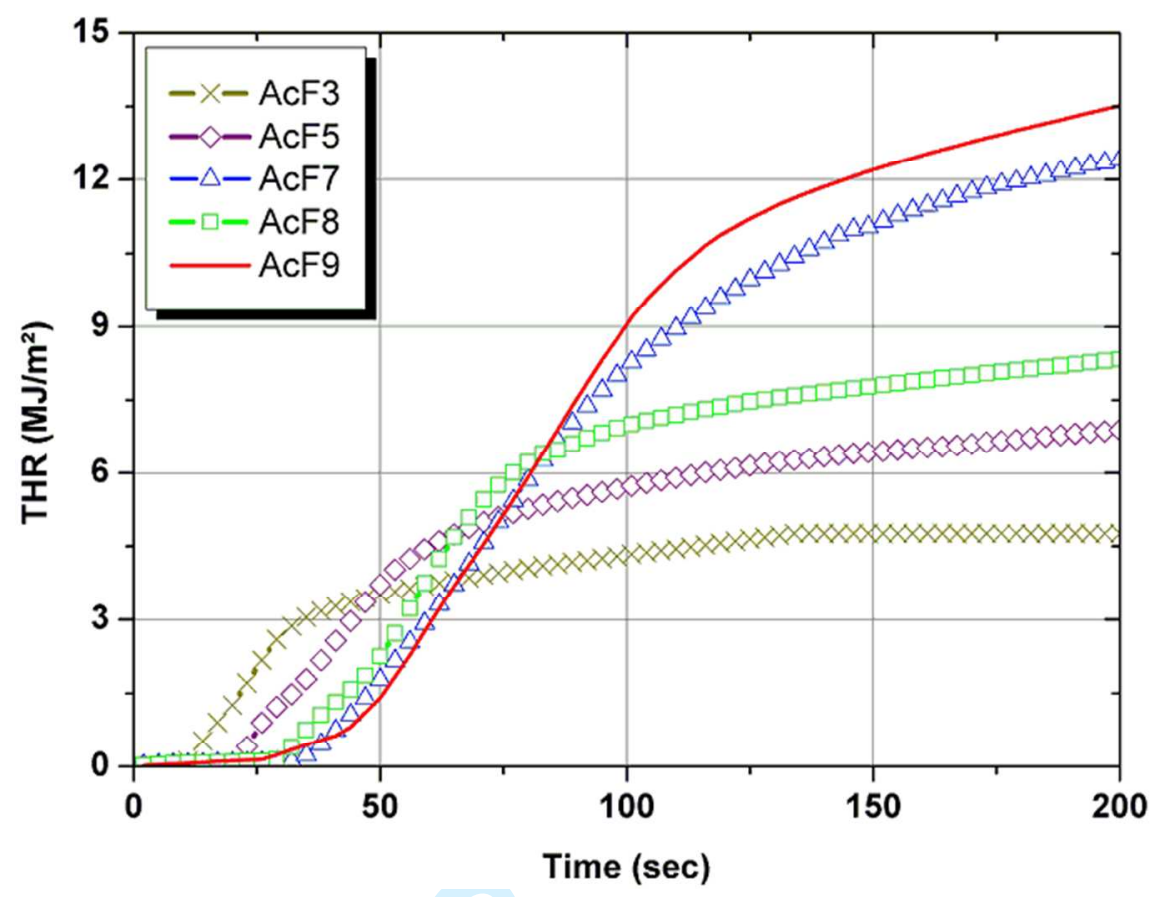

Figure 8: Peak heat release rates as a function of $\mathrm{N}^{\circ}$ plies.

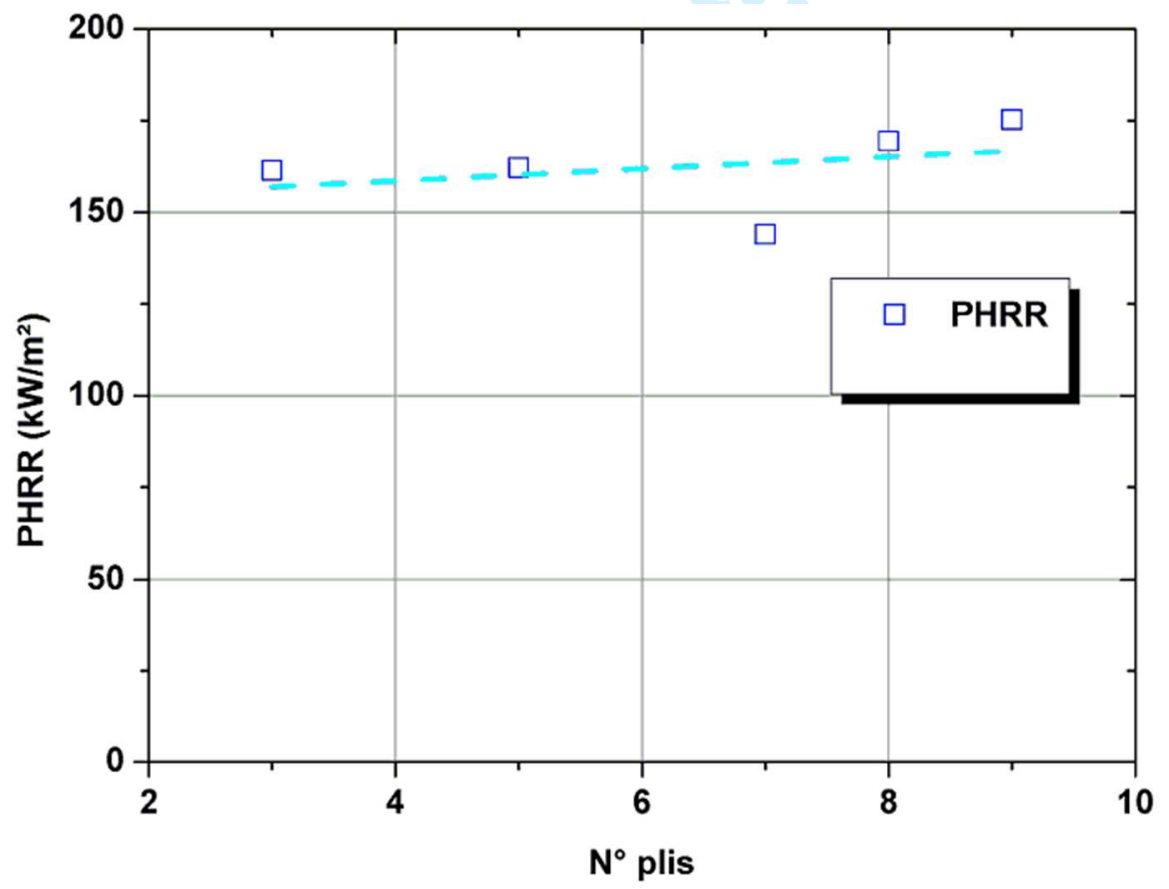

https://mc.manuscriptcentral.com/jfsciences 
Figure 9: Mass loss as a function of number plies for the phenolic composites.

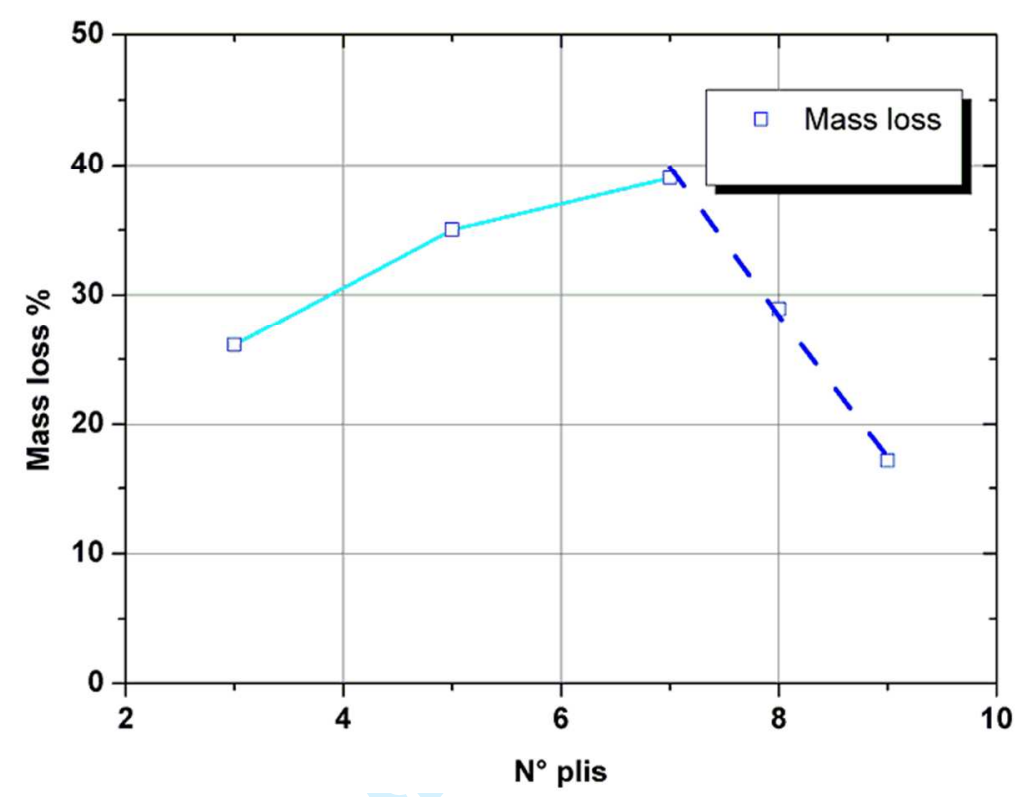

Figure 10: $\mathrm{CO}_{2}$ production rates for epoxy composites as a function of time at $50 \mathrm{~kW} / \mathrm{m}^{2}$.

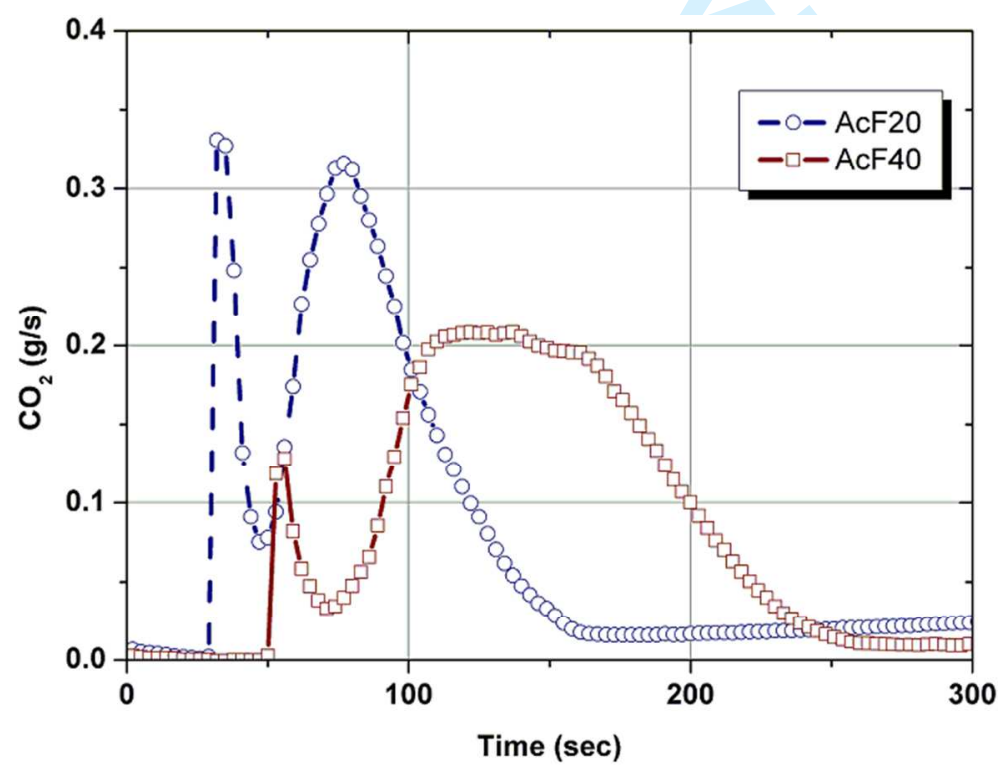


Figure 11: $\mathrm{CO}_{2}$ production rates for phenolic composite materials as a function of time at 50 $\mathrm{kW} / \mathrm{m}^{2}$.

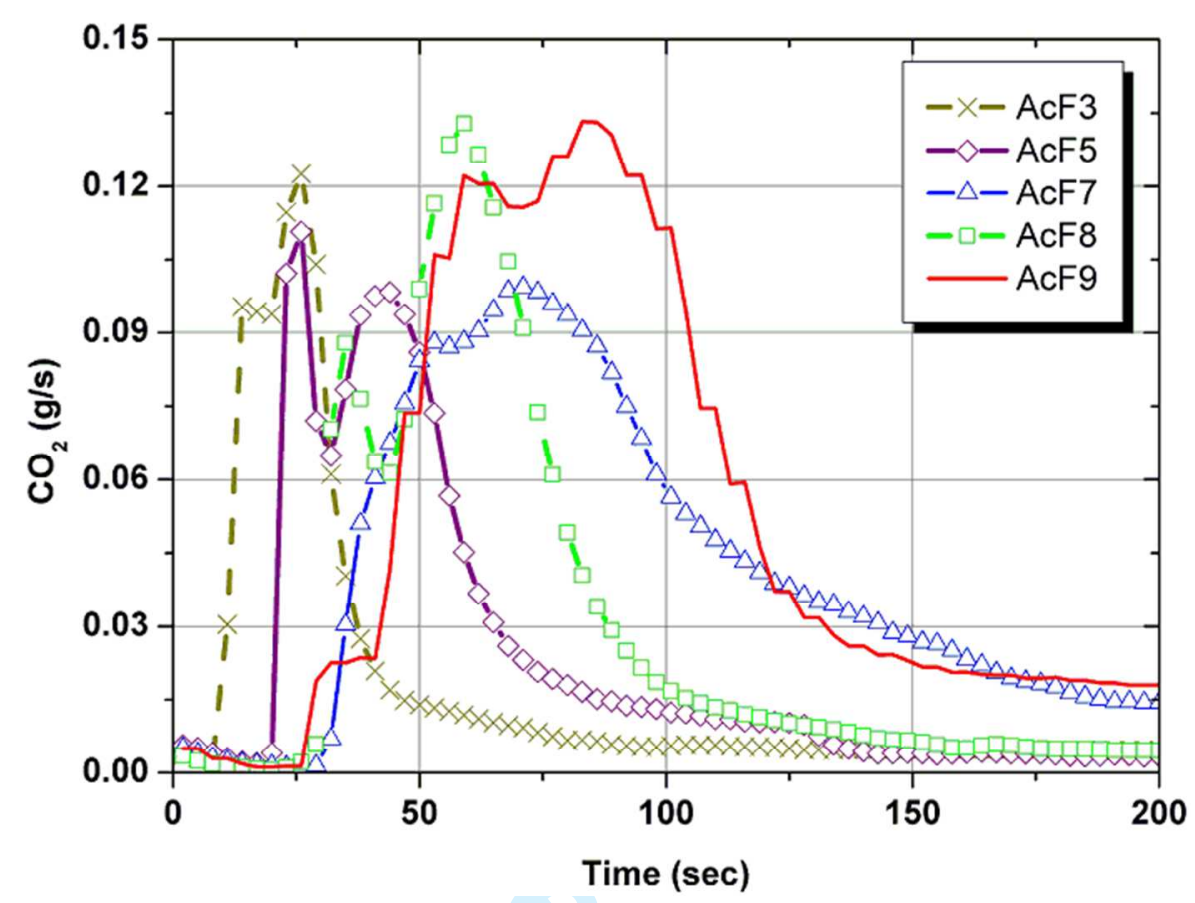

Figure 12: Smoke production rates for the epoxy composites as a function of time at $50 \mathrm{~kW} / \mathrm{m}^{2}$.

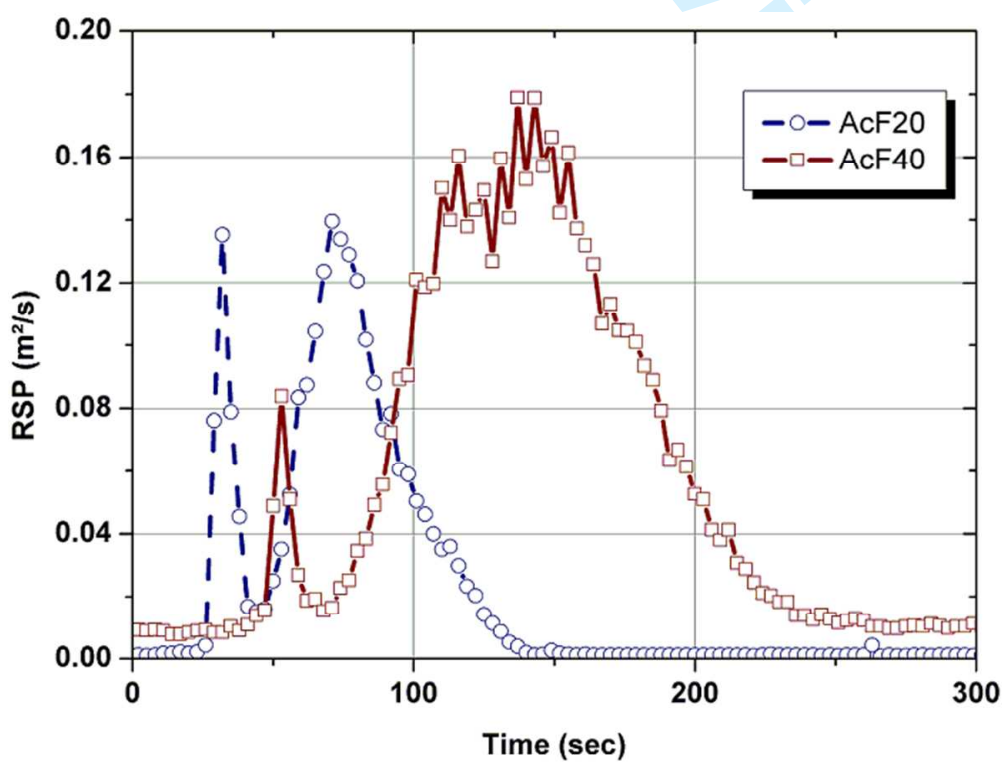

https://mc.manuscriptcentral.com/jfsciences 
Figure 13: Smoke production rates for phenolic composites as a function of time at $50 \mathrm{~kW} / \mathrm{m}^{2}$.

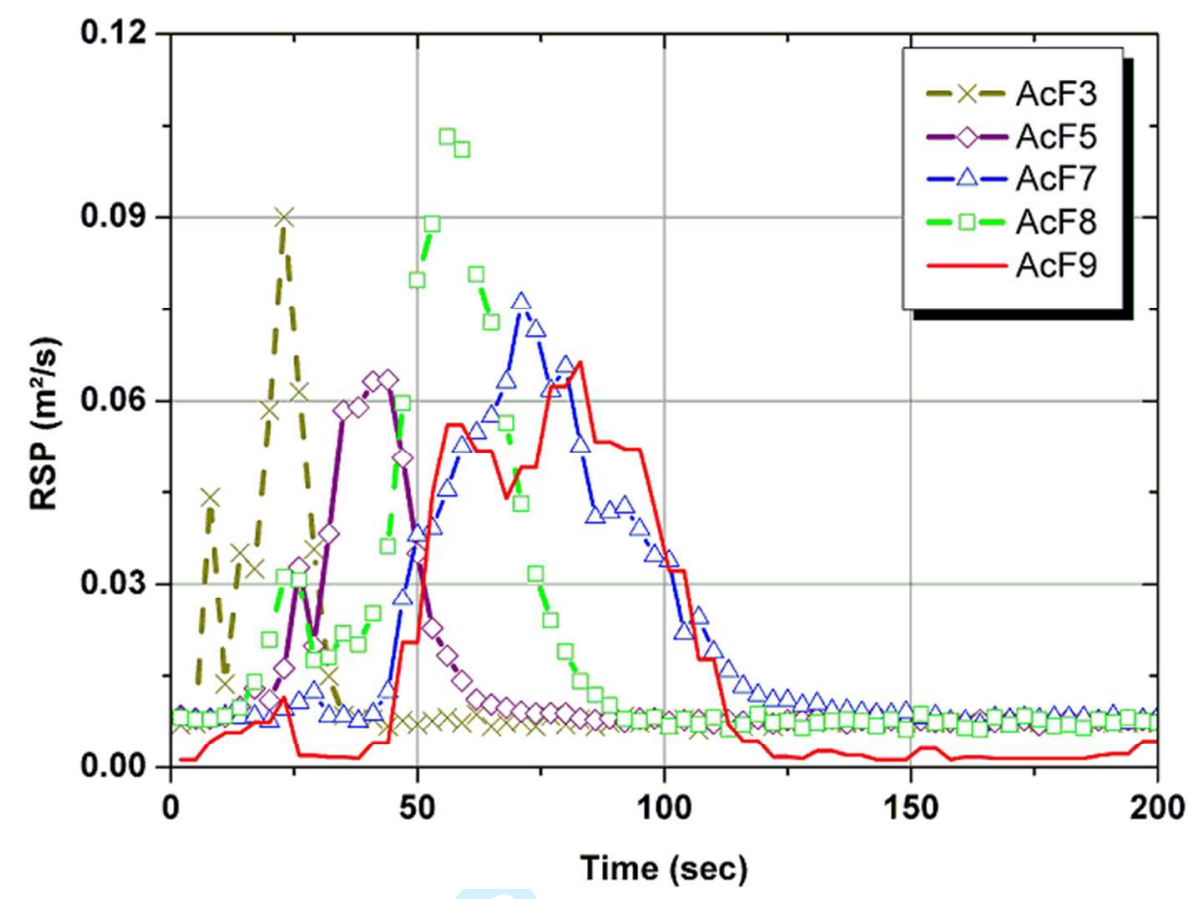

Figure 14: Total smoke produced for the epoxy composite material as a function of time at 50 $\mathrm{kW} / \mathrm{m}^{2}$.

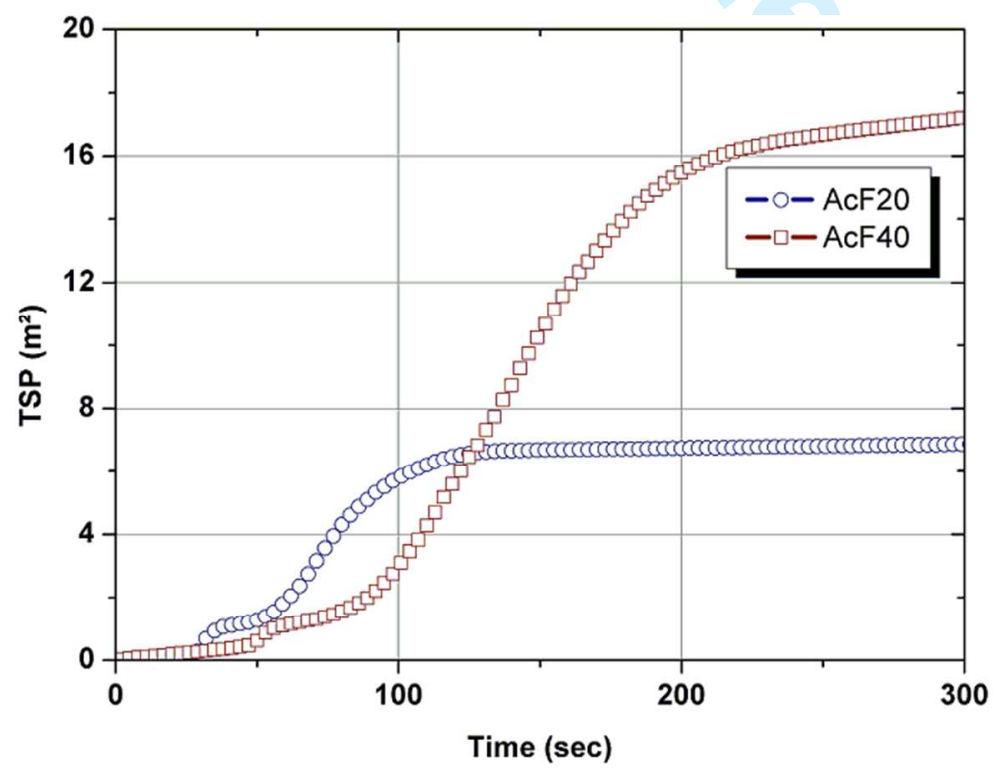

https://mc.manuscriptcentral.com/jfsciences 
Figure 15: Total smoke produced for phenolic composites as a function of time at $50 \mathrm{~kW} / \mathrm{m}^{2}$.

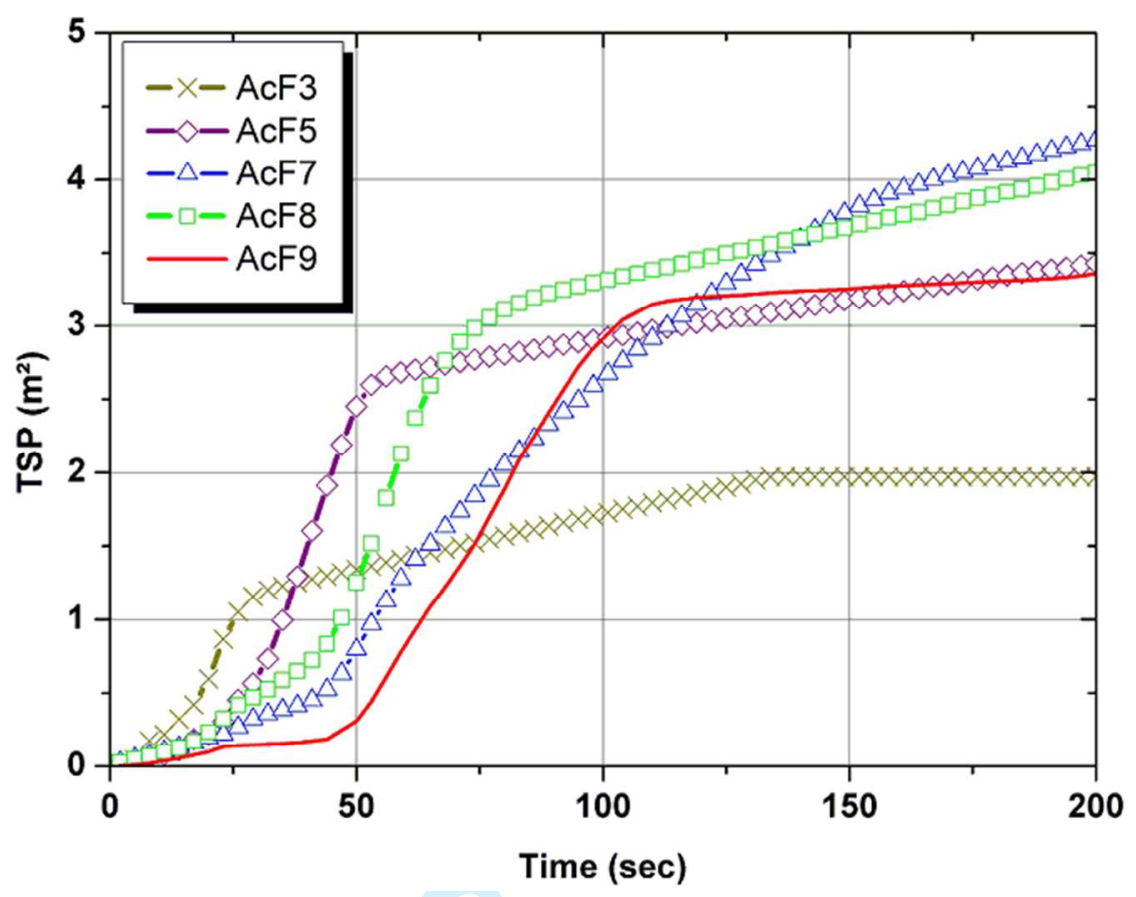

Figure 16: Smoke yields as a function of the number layers of the phenolic resins.

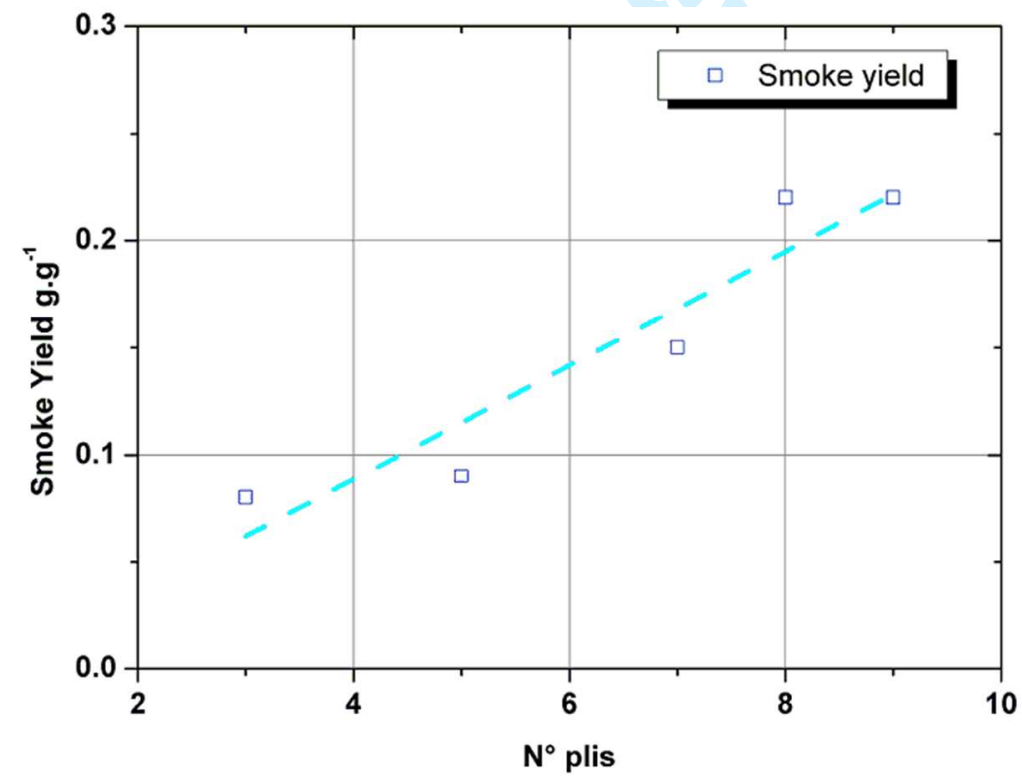

https://mc.manuscriptcentral.com/jfsciences 